\title{
Seasonality of the copepod assemblages associated with interplay waters off northeastern Taiwan
}

\author{
Li-Chun Tseng $\cdot$ Jia-Jang Hung • \\ Qing-Chao Chen $\cdot$ Jiang-Shiou Hwang
}

Received: 17 April 2012/Revised: 20 October 2012/ Accepted: 1 November 2012/Published online: 18 November 2012

(C) Springer-Verlag Berlin Heidelberg and AWI 2012

\begin{abstract}
This study investigated copepod assemblages in the regime around Turtle Island off northern Taiwan to trace South China Sea water (SCSW) flowing northward with the Kuroshio Current. Seasonal variations of copepod assemblages demonstrated a dynamic succession of changes in copepod populations; the average abundance for total copepods ranged from $102.58 \pm 53.38$ in December to $1669.89 \pm 1866.17$ in March (individuals $\mathrm{m}^{-3}$ ). A total of 87 copepod species representing 36 genera and 21 families were identified. Among all samples, Temora turbinata dominated the copepods by a relative abundance (RA) of $26.89 \%$, followed by Paracalanus parvus (RA: $22.34 \%$ ) and Corycaeus (Ditrichocorycaeus) affinis (RA: $12.77 \%$ ). Only the Acrocalanus gracilis species was recorded in all samples. Results of one-way ANOVA revealed that the number of copepod species, indices of richness, evenness, and Shannon-Wiener diversity differed significantly in five different cruises. The density of five copepod species (Gaetanus minor, Calanus sinicus, Eucalanus elongates, Rhincalanus nasutus, and Rhincalanus rostrifrons) exhibited a significant negative
\end{abstract}

Communicated by H.-D. Franke.

L.-C. Tseng · J.-S. Hwang $(\bowtie)$

Institute of Marine Biology,

National Taiwan Ocean University, Keelung 202, Taiwan

e-mail: jshwang@mail.ntou.edu.tw

L.-C. Tseng

e-mail: lichun@mail.bestredeye.org

J.-J. Hung

Institute of Marine Geology and Chemistry,

National Sun Yat-Sen University, Kaohsiung, Taiwan

Q.-C. Chen

South China Sea Institute of Oceanography,

Academia Sinica, Guangzhou, China correlation with seawater temperature. In contrast, the density of Canthocalanus pauper and Undinula vulgaris was significantly positively correlated with seawater temperature. The cold-water indicator species, $C$. sinicus, recorded in samples of March and May indicated the effect of China Coast Water (CCW) on copepod communities in the study area. Furthermore, the presence of Calanoides philippinensis in May samples strongly indicated that the SCSW may reach the Turtle Island area. Consequently, C. philippinensis and C. sinicus can be used to trace SCSW and CCW, respectively, in the study area.

Keywords Indicator species - Copepod assemblages . Succession $\cdot$ East China Sea $\cdot$ Kuroshio Current

\section{Introduction}

Distributions of water masses crucially affect the composition and abundance of oceanic biota around the island of Taiwan (Hwang et al. 2004, 2006, 2010; Dur et al. 2007; Tseng et al. 2008a, b, d, 2011a, c). Two crucial water masses may meet in the coastal sea off northern Taiwan. The Kuroshio Current (KC) brings the warm-water mass along the eastern coast of Taiwan, and the China Coastal Current (CCC) may transport the cold-water mass to the area during the northeast monsoon season (Jan et al. 2002). These two water types can be differentiated by a notable difference in temperature and salinity. When these two water masses meet in an area off northeastern Taiwan, their interplay creates diverse habitats with dynamic spatial and temporal variations of environmental parameters. Such a complex water system may provide diverse habitats for marine biota. Therefore, Shao (1998) estimated that approximately $10 \%$ of marine species worldwide can be found in waters around Taiwan. 
Marine creatures are sensitive to environmental changes, which may cause physical and physiological damage and/or death under extreme conditions (Peng et al. 2011; Tseng et al. 2011b; Chan et al. 2012). Most zooplankton biota are characterized by a short life span, small body size, and live their entire lives in water and are generally sensitive to hydrographic conditions (Webber et al. 2005). Thus, planktonic biota have been used as indicators to study the movement of water masses (e.g., copepods) (Hwang and Wong 2005; Hsiao et al. 2011b), water pollution (e.g., polychaeta) (Grassle and Grassle 1976; Fielman et al. 2001; Dean 2008), and water quality (e.g., crustaceans, rotifers, phytoplankton, and zooplankton,) (Gannon and Stemberger 1978; Webber et al. 2005).

In northern Taiwan, several studies indicated that the copepod $C$. sinicus is a crucial indicator species for cold-water masses derived from the Bohai Sea and the Yellow Sea (Hwang et al. 2006; Hwang and Wong 2005; Dur et al. 2007; Tseng et al. 2008b, 2012). To date, no characteristic species of copepod in the coastal sea off northern Taiwan has been reported as an indicator of South China Sea water (SCSW).

Therefore, the present study aimed to reveal: (1) the Kuroshio Current transports a characteristic species of copepod living in the South China Sea (SCS) to the study area and (2) the abundance, species richness, and composition of copepods exhibit strong seasonal succession in the study area.

\section{Materials and methods}

Study area and sampling

Samples were obtained from five sampling stations around Turtle Island off northeastern Taiwan (Fig. 1; Table 1) to investigate the succession of copepod community and search for the indicator species of copepod in water masses of East China Sea (ECS) and SCS.

The study was conducted onboard the Ocean Research Vessel II during cruises 1700, 1716, 1738, 1747, and 1756 during March, May, August, September, and December 2010. The copepod samples were collected at each station by using surface tows $(0-5 \mathrm{~m})$ with a standard North Pacific zooplankton net (mouth diameter of $45 \mathrm{~cm}$ and mesh size of $333 \mu \mathrm{m}$ ). A Hydrobios flowmeter (Germany) was mounted at the center of the net mouth. Temperature and salinity were recorded with a Seabird CTD instrument prior to collection of zooplankton samples. Zooplankton samples were preserved immediately in seawater containing $5 \%$ buffered formaldehyde.

Identification and enumeration of zooplankton

In the laboratory, samples were split by a Folsom plankton splitter until the subsample contained less than 500
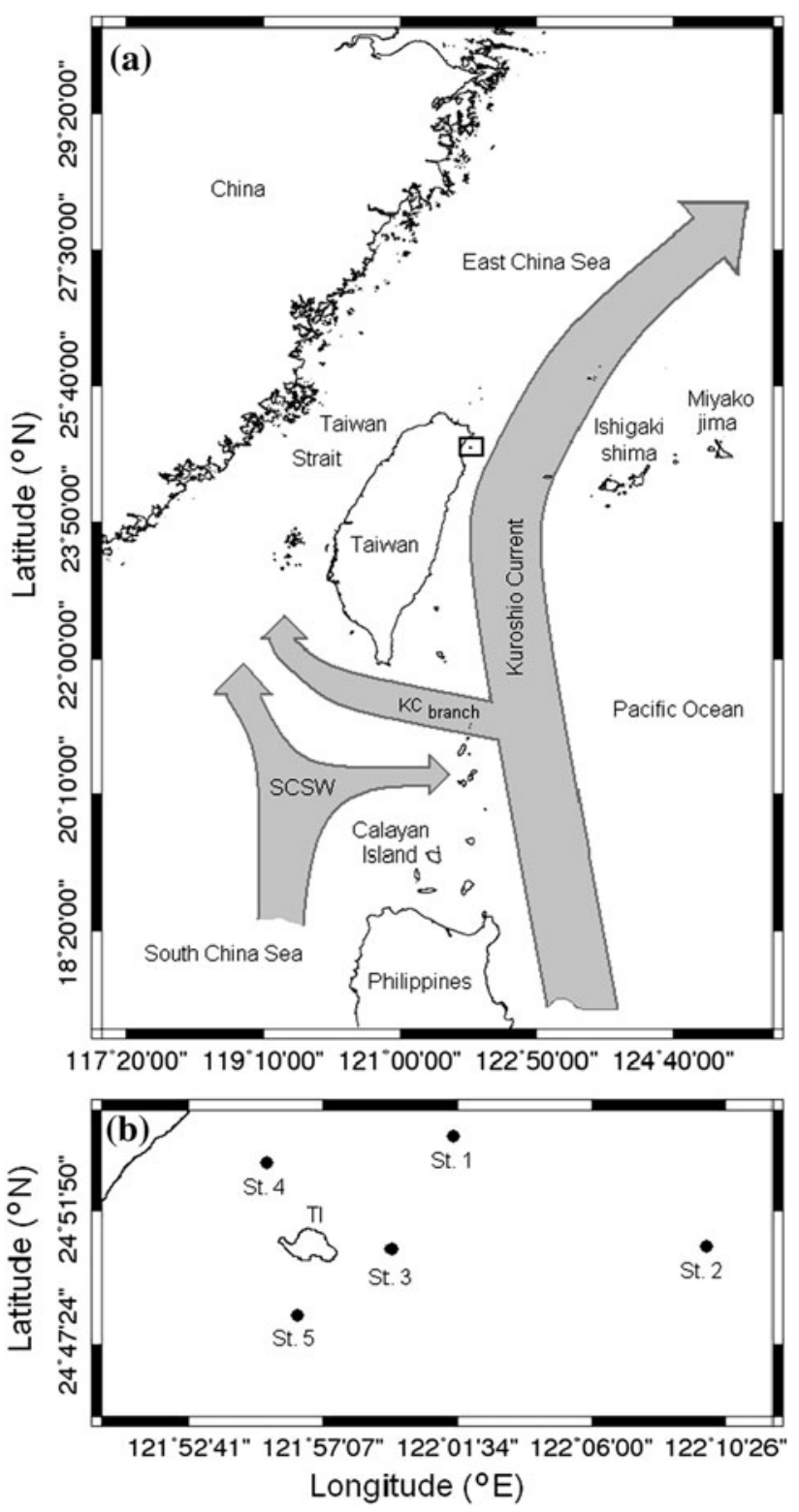

Fig. 1 Map of the study area (a) and sampling locations (b) around Turtle Island during various seasons in 2010. KC Kuroshio Current, $S C S W$ South China Seawater, and TI location of Turtle Island

specimens. Adult copepods were sorted and identified to species level by using the keys of Chen and Zhang (1965), Chen et al. (1974), Yamaji (1996), and Chihara and Murano (1997). The total number of individuals (ind.) of each copepod taxon was recorded, and the density (ind. $\mathrm{m}^{-3}$ ) was calculated.

Statistical analyses

We analyzed the copepod community of each sample by applying the Paleontological Statistics (PAST) computer package (Hammer et al. 2001) to elucidate the temporal variations of copepod assemblages in various periods. The 
Table 1 Location, sampling time, and sampling cruises of this study around Turtle Island in 2010

\begin{tabular}{|c|c|c|c|c|c|c|c|}
\hline \multirow[t]{2}{*}{ Station } & \multicolumn{2}{|l|}{ Location } & \multicolumn{5}{|c|}{ Sampling time } \\
\hline & $\begin{array}{l}\text { Longitude } \\
\left({ }^{\circ} \mathrm{E}\right)\end{array}$ & $\begin{array}{l}\text { Latitude } \\
\left({ }^{\circ} \mathrm{N}\right)\end{array}$ & $\begin{array}{l}\text { Mar. OR II } \\
\text { CR } 1700\end{array}$ & $\begin{array}{l}\text { May OR II } \\
\text { CR } 1716\end{array}$ & $\begin{array}{l}\text { Aug. OR II } \\
\text { CR } 1738\end{array}$ & $\begin{array}{l}\text { Sept. OR II } \\
\text { CR } 1747\end{array}$ & $\begin{array}{l}\text { Dec. OR II } \\
\text { CR } 1756\end{array}$ \\
\hline St. 1 & $122^{\circ} 0^{\prime} 16.52^{\prime \prime}$ & $24^{\circ} 53^{\prime} 5.25^{\prime \prime}$ & $22: 07$ & 06:09 & $14: 42$ & $17: 24$ & $15: 34$ \\
\hline St. 2 & $122^{\circ} 9^{\prime} 9.50^{\prime \prime}$ & $24^{\circ} 50^{\prime} 7.63^{\prime \prime}$ & $16: 40$ & $03: 45$ & $13: 31$ & $15: 12$ & $13: 43$ \\
\hline St. 3 & $121^{\circ} 59^{\prime} 3.87^{\prime \prime}$ & $24^{\circ} 50^{\prime} 8.78^{\prime \prime}$ & $00: 38$ & $07: 10$ & $15: 54$ & $10: 20$ & $16: 30$ \\
\hline St. 4 & $121^{\circ} 55^{\prime} 14.35^{\prime \prime}$ & $24^{\circ} 52^{\prime} 5.05^{\prime \prime}$ & $07: 49$ & 09:40 & $18: 40$ & $02: 55$ & $19: 22$ \\
\hline St. 5 & $121^{\circ} 56^{\prime} 8.12^{\prime \prime}$ & $24^{\circ} 48^{\prime} 2.25^{\prime \prime}$ & $03: 45$ & $08: 30$ & $17: 00$ & $19: 32$ & $17: 33$ \\
\hline
\end{tabular}

copepod species diversity of each sample was estimated as the Shannon-Wiener diversity, and indices of Pielou's evenness and Margalef richness were applied to analyze the copepod community structure.

The abundance of copepod species of whole samples was used to calculate similarities before clustering. We used the functional test by Box and Cox (1964) for transformation of data before conducting similarity analysis to reduce the bias of considerably abundant species. The value $(\lambda)$ of power transformation was 0.82 . Furthermore, the data of original species abundance were subsequently transformed by using $\log _{10}(x+1)$ to logarithmic transformation densities for all samples. The Bray-Curtis similarity (Michie 1982) was applied to measure the distance between samples and copepod community before non-metric multidimensional scaling (NMDS) analysis and cluster analysis.

The data of 25 samples included 87 species were applied with NMDS analysis to demonstrate the variation among sampling cruises. Further, cluster analysis was applied to reveal the communities of copepod species that were identified in similar water masses. Among the 25 samples, the 16 dominant copepod species with a relative abundance value of over $0.5 \%$ (comprising $94.54 \%$ of the total copepod) were computed by using cluster analysis to evaluate the relative similarity of distribution patterns among all samples for reducing the interference with estimating the relationship between copepod community and water temperature.

Pearson's product moment correlation was used to estimate the relationship among copepod abundance, temperature, and salinity. One-way ANOVA with post hoc Turkey's HSD (honestly significant difference) test was applied to identify differences in copepod abundance among seasons and stations.

\section{Results}

\section{Hydrological structures}

Satellite images of sea surface temperatures (SSTs) from March 2010 (Fig. 2a) to December 2010 (Fig. 2e) revealed the characteristics of interaction between $\mathrm{CCC}$ and $\mathrm{KC}$ in and around the study area. The cold-water masses of CCC influenced the study area during the prevailing periods of the northeastern monsoon (November-April). The influence of cold-water masses of CCC was stronger in March (Fig. 2a) than in May (Fig. 2b). Furthermore, the warm KC intruded to the study area during prevailing periods of the southwestern monsoon (June-October). The temperature of surface water was higher than $27{ }^{\circ} \mathrm{C}$ during August (Fig. 2c) and September (Fig. 2d). In December, the CCC appeared to flow to the study area through the northwestern part of the Taiwan Strait (Fig. 2e).

Figure 3 shows the relationship between seawater temperature and salinity for each station during five sampling cruises. During March, seawater temperatures varied significantly among sampling stations. The water properties may exist between CCW (Stations 3-5) and Kuroshio water $(\mathrm{KW})$ (Stations 1-2) off northeastern Taiwan. The water properties between April and September are similar to KW. The water in August and September may have been dominated by $\mathrm{KW}$, as revealed by the relatively high temperature and salinity. In December, the CCC may intrude into the study area because the water was characterized by relatively lower temperature, as shown in the T-S diagram (Fig. 3).

\section{Copepod community structure}

From the 25 samples collected from five cruises, 87 copepod species were identified from 36 genera and 21 families, including Calanoida, Cyclopoida, Harpacticoida, and Poecilostomatoida (Table 2). Figure 4 shows the variation of copepod abundance, species number (Fig. 4a), indices of species richness, Shannon-Wiener diversity, and evenness (Fig. 4b) at each sampling station. The lowest abundance of total copepod in our samples was 17.65 (ind. $\mathrm{m}^{-3}$ ) at Station 2 in December 2010, whereas the highest abundance was 5000.84 (ind. $\mathrm{m}^{-3}$ ) at Station 1 in March 2010 (Fig. 4a). The highest copepod abundance recorded at Station 1 in March 2010 may be attributed to KW (Fig. 3). The number of copepod species identified at each station 
(a) Mar./2010

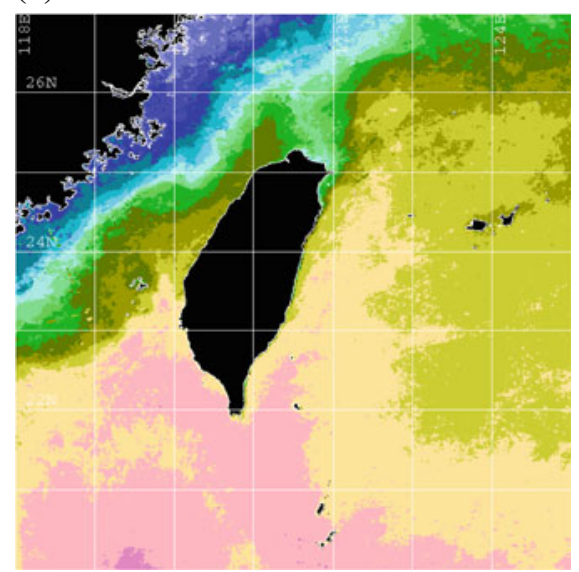

(b) May/2010

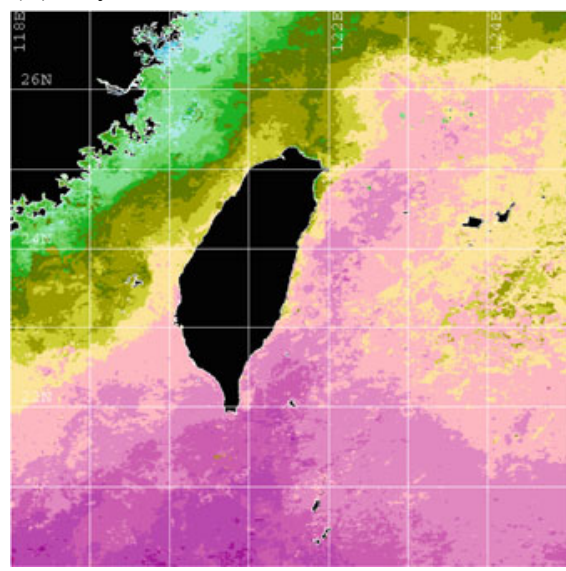

(d) Sep./2010

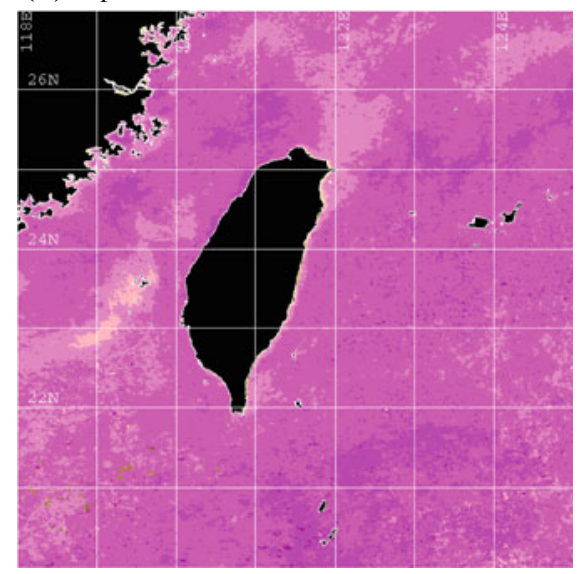

(e) Dec./2010

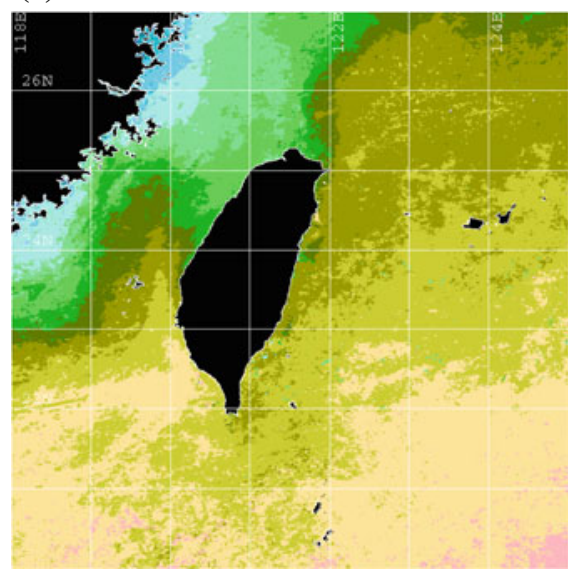

(c) Aug./2010
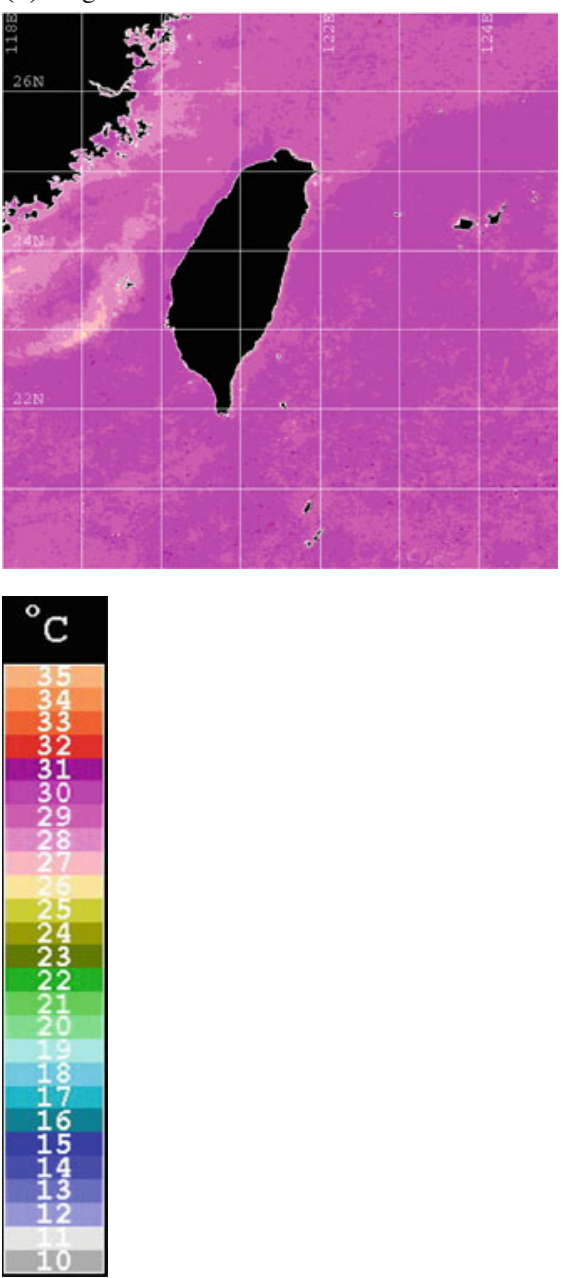

Fig. 2 Satellite images of monthly average sea surface temperatures (SSTs). The images were selected from March (a), May (b), August (c), September (d), to December (e) in 2010

ranged from 10 (Station 1 in March) to 42 (Station 1 in May) (Fig. 4a). The richness index of sampling stations ranged from 1.32 at Station 3 in August 2010 to 7.64 at Station 1 in May 2010. The Shannon-Wiener diversity index of sampling stations ranged from 0.52 at Station 5 in August 2010 to 3.0 at Station 1 in December 2010. Similarly, Pielou's evenness index of sampling stations ranged from 0.16 at Station 5 in August 2010 to 0.86 at Station 1 in December 2010 (Fig. 4b).

The average abundance of five sampling cruises for copepods ranged from $102.58 \pm 53.38$ inds. $/ \mathrm{m}^{3}$ (December 2010 ) to $1669.89 \pm 1866.17$ inds. $/ \mathrm{m}^{3}$ (March 2010) (Table 2). Among all samples, the five most abundant species were dominated by Temora turbinata (relative abundance, RA: $26.89 \%$ ), Paracalanus parvus (RA: $22.34 \%$ ), Corycaeus (Ditrichocorycaeus) affinis (RA: $12.77 \%$ ), Paracalanus nanus (RA: $9.54 \%$ ), and C. sinicus (RA: $7.83 \%$ ). The total number of the five most abundant species accounted for $79.37 \%$ of the total abundance of all samples (Table 2). Calanoida copepod A. gracilis was recorded in all samples with a $100 \%$ occurrence rate (OR). The four species T. turbinata, U. vulgaris, C. pauper, and Temora discaudata accounted for $84 \%$ OR. Among taxon results, 19 copepod species with the lowest value of OR $(4.0 \%)$ were identified from a single sample (Table 2). The present study records the highest abundance of total copepod at Station 1 in March 2010 (Fig. 4a) that might be caused by KW (Fig. 3). The top three dominant species at Station 1 were C.(D.) affinis (2154.36 inds. $/ \mathrm{m}^{3}$ ), P. parvus (2027.63 inds. $/ \mathrm{m}^{3}$ ), and C. sinicus $\left(136.48\right.$ inds. $\left./ \mathrm{m}^{3}\right)$, with RA 43.08, 48.97, and $2.73 \%$, respectively.

Figure 5 shows the variation of proportion in the five most dominant copepod species at each sampling cruise. The dynamic proportion of each sampling cruise indicated a clear succession. The species $C$. sinicus, $P$. parvus, and Corycaeus (D.) affinis were dominant in March and May, when cold-water masses of CCC reached the area off northeastern Taiwan. T. turbinata, U. vulgaris, and 


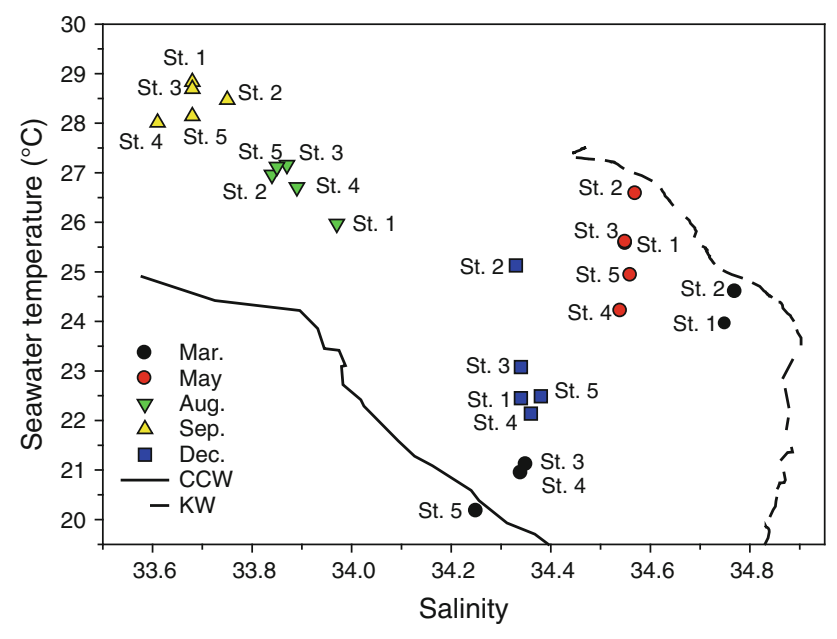

Fig. 3 Temperature and salinity of all stations during each sampling cruise. The T-S diagram shows the distribution of $\mathrm{T}$ and $\mathrm{S}$ in each station in five sampling cruises. The solid and dotted lines of $\mathrm{T}-\mathrm{S}$ curves represent the CCW (plume of Yangtze River; $30^{\circ} 30^{\prime} \mathrm{N} ; 122^{\circ}$ $52^{\prime} \mathrm{E}$ ) and $\mathrm{KW}$ (Kuroshio water; $25^{\circ} 10^{\prime} \mathrm{N} ; 123^{\circ} 10^{\prime} \mathrm{E}$ ) recorded from a cruise on July 15 to July 29,2001

C. pauper were dominant in August and September with high temperature (Fig. 3). The species T. turbinata exhibited relatively high RA values in May (2.89\%), August (76.79 \%), and September (23.75\%). Paracalanus nanus was dominant in May, September, and December. Paracalanus aculeatus (RA $15.78 \%$ ) and Clausocalanus arcuicornis (RA 18.23) were dominant only in September and December, respectively (Fig. 5).

\section{Statistical analysis}

Among five sampling cruises, multiple comparisons of mean values (Table 2) were conducted through one-way ANOVA, followed by the Tukey's test (Fig. 6). Results of one-way ANOVA demonstrated no significant difference among all sampling cruises $(p>0.05$, Fig. 6a). The number of copepod species was significantly larger in May samples than in the August $(p=0.004)$ and September ( $p=0.012$ ) samples (Fig. 6b). The richness index was significantly larger in May than in March $(p=0.04)$, August $(p=0.003), \quad$ and September $(p=0.01)$. The richness index was also significantly greater in December than in August $(p=0.008)$ and September ( $p=0.027$ ) (Fig. 6c). By contrast, the evenness index was significantly lower in March than in September $(p=0.012)$ and December $(p=0.001)$ (Fig. 6d). The Shannon-Wiener diversity index was significantly greater in December than in March $(p=0.002)$ and August ( $p=0.027$ ) (Fig. 6e).

Only a few copepod species demonstrated a change in density that significantly correlated with seawater temperature. For example, the abundance of $G$. minor $(r=-0.403, p=0.046), C$. sinicus $(r=-0.46, p=$ $0.021)$, E. elongates $(r=-0.589, p=0.002), R$. nasutus ( $r=-0.403, p=0.046)$, and $R$. rostrifrons $(r=-0.709$, $p<0.001)$ exhibited a significantly negative correlation with water temperature. By contrast, the densities of two copepod species, $C$. pauper $(r=0.461, p=0.02)$ and $U$. vulgaris $(r=0.414, P=0.039)$, exhibited a significantly positive correlation with seawater temperature.

Copepod association analysis

Figure 7 shows the NMDS results derived from all copepod data of 25 samples collected from five different sampling months. The compositions of copepod assemblages in samples of different months were separated (Fig. 7), which further revealed a differential grouping pattern of copepod communities in comparison with samples collected from various water masses. The species association of the 16 most abundant species was evaluated by normalized BrayCurtis distances. Species with similar distribution patterns formed clusters that revealed the extent of co-occurrence of copepod species (Fig. 8). Table 3 lists samples and their mean temperature for associated copepod species of cluster grouping results.

The first assemblage (Group I B) displayed its principal association in samples of March and May, which was characterized by low water temperature $\left(24.30 \pm 2.58{ }^{\circ} \mathrm{C}\right.$, Table 3). These three species were not identified in September, when seawater temperature was high (Table 3). The second group (Group II A) contained only two copepod species, Paracalanus nanus and Paracalanus aculeatus. These two species did not appear in March. In particular, calanoida copepod Paracalanus aculeatus was only identified in September. The average temperature of these two species was in the range of $25.9 \pm 2.39{ }^{\circ} \mathrm{C}$. The third group (Group II B) included 11 copepod species. These copepods were identified in all five sampling cruises, and they belong to common native species in waters around Turtle Island. The average temperature of these two species was in the range of $25.16 \pm 2.58{ }^{\circ} \mathrm{C}$ (Table 3 ). Results of cluster grouping of communities indicated that the copepod assemblage was affected by the interplay of water masses during various periods. This phenomenon implies a substantial succession in copepod communities in the area off northeastern Taiwan (Fig. 8).

\section{Discussion}

Dominant copepod species and seasonality

Previous studies reported that copepod communities in coastal seas off northern Taiwan exhibited a clear seasonal 


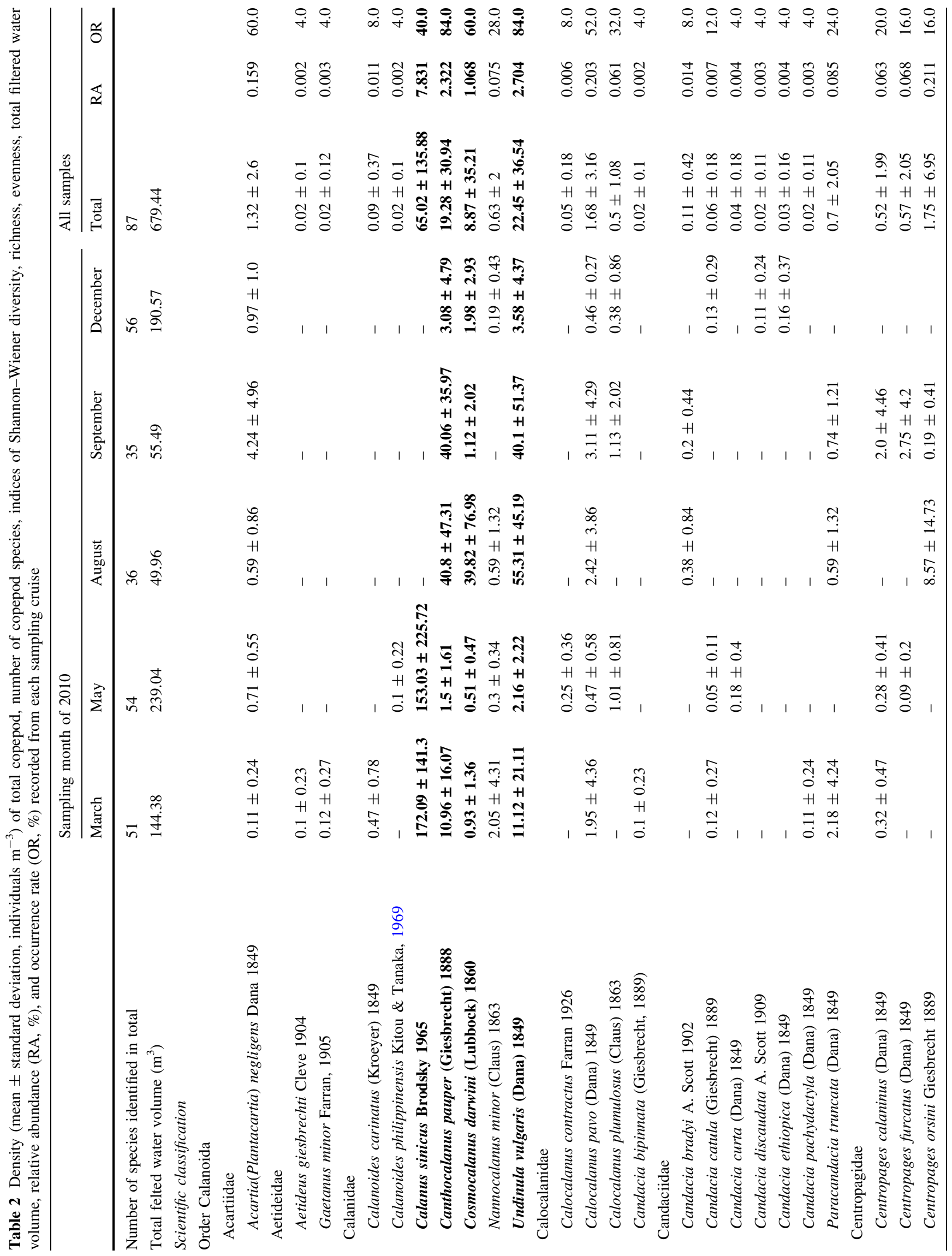




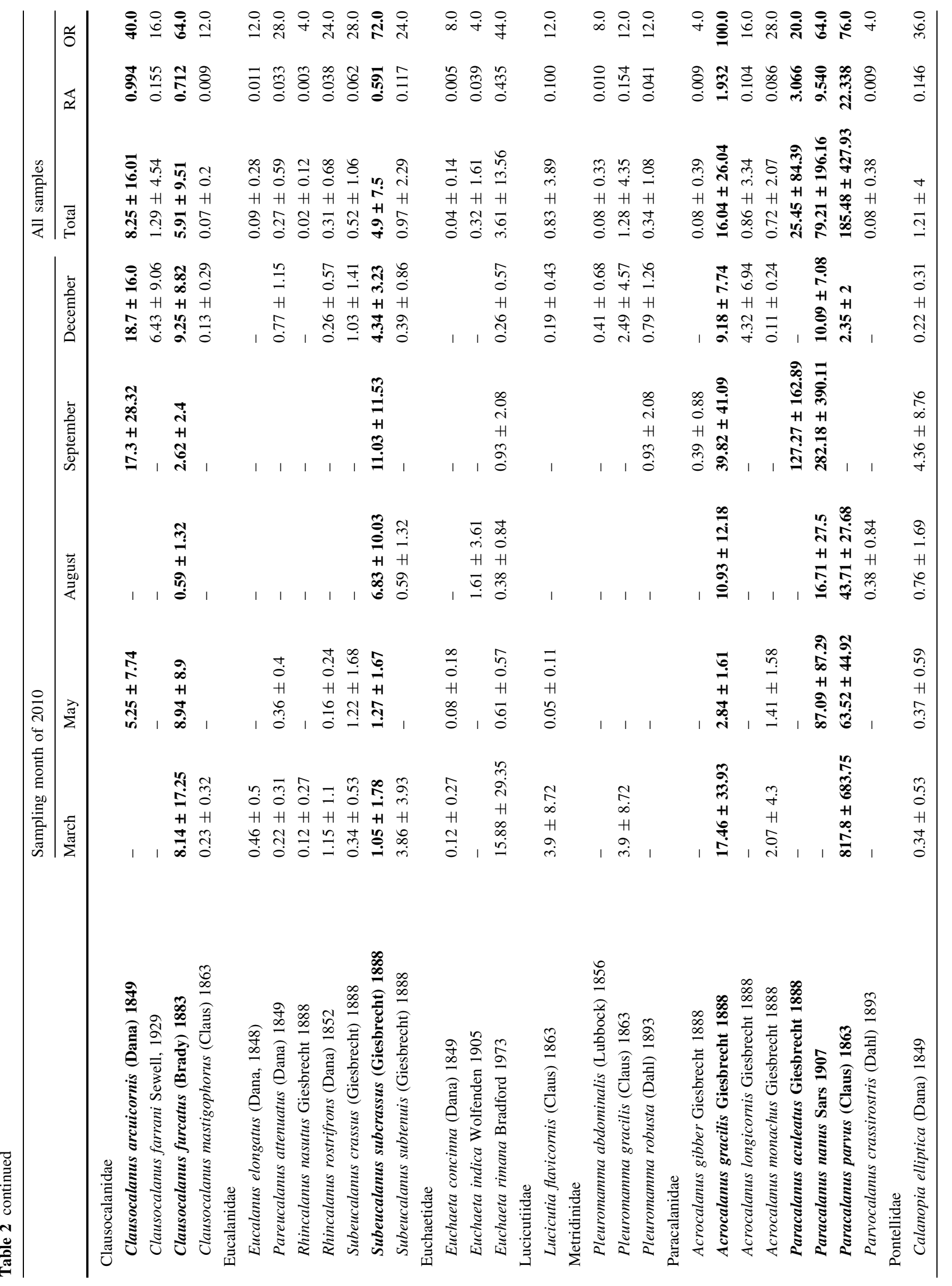




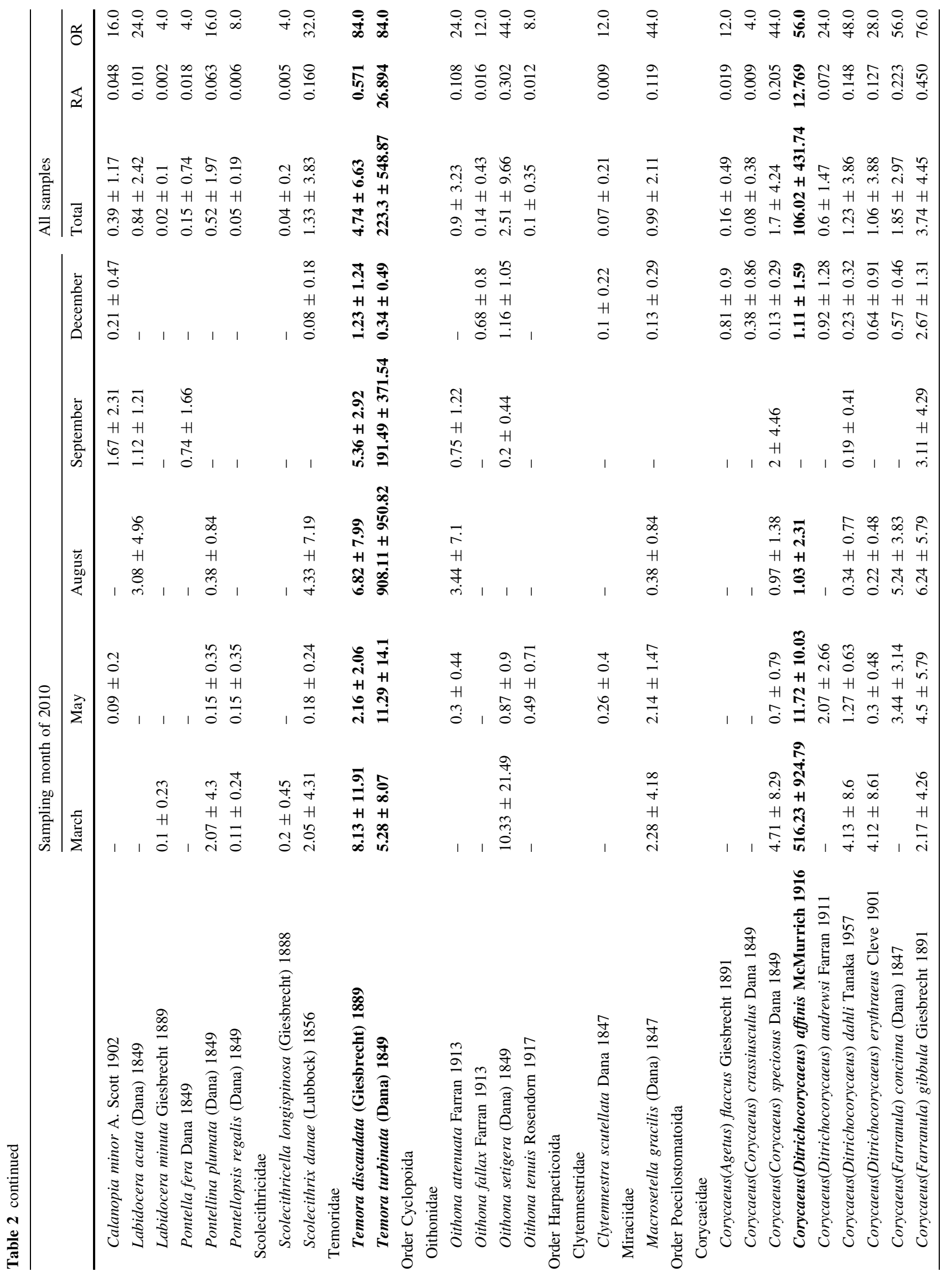




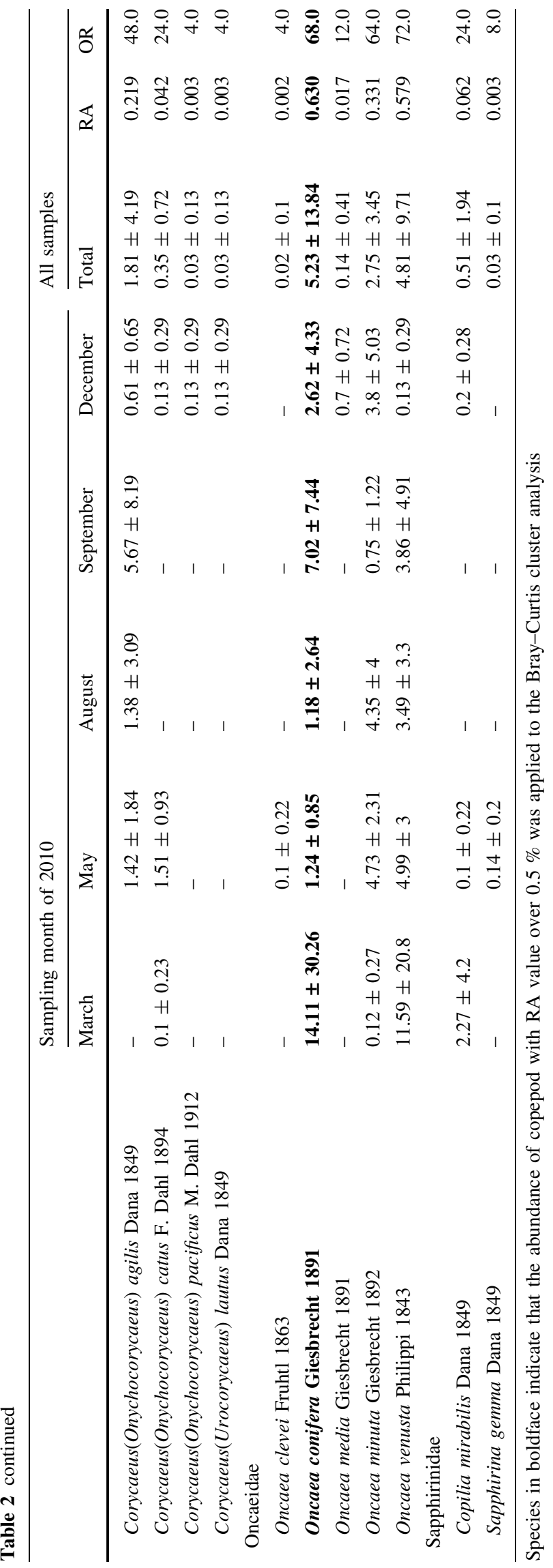

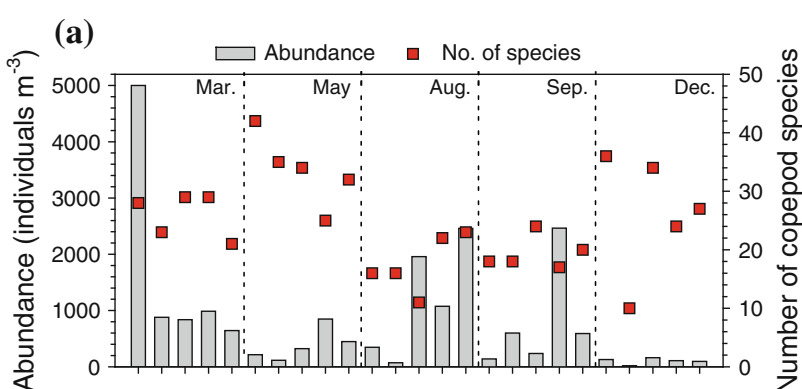

(b)

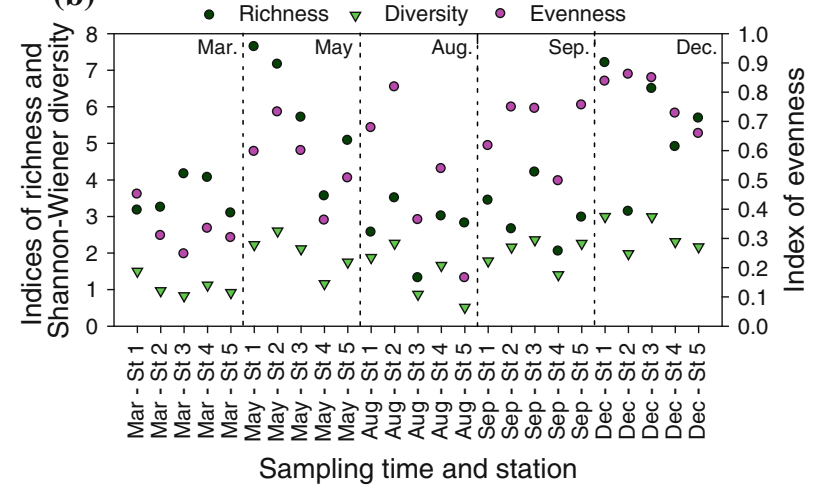

Fig. 4 Distributions of copepod density and species number (a), indices of richness, evenness, and Shannon-Wiener diversity (b) during five sampling cruises

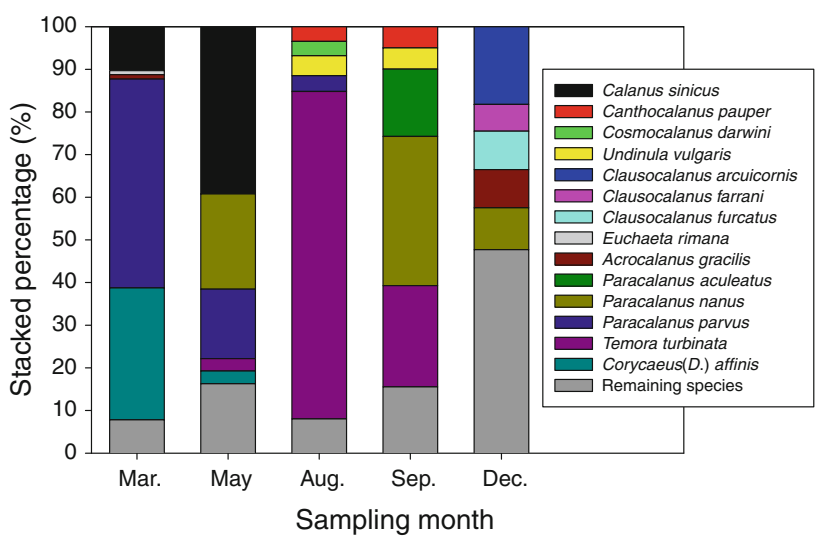

Fig. 5 Relative abundance (proportion) of the five most dominant species in each sampling cruise

succession (Hwang et al. 2004, 2006; Dur et al. 2007; Tseng et al. 2008b). In this study, the community analysis demonstrated a rapid dynamic in a monthly scale in samples between August and September, indicating that the interaction and mixing of water masses was noticeable (Fig. 7). The present results show that three copepod species belong to the cold-water species: P. parvus, C.(D.) affinis, and C. sinicus (Group I B, Fig. 8; Table 3). Hwang et al. (2006) reported the 5-year investigation of copepod communities in estuarine water at northwestern Taiwan. C. sinicus and C.(D.) affinis were identified as the dominant 

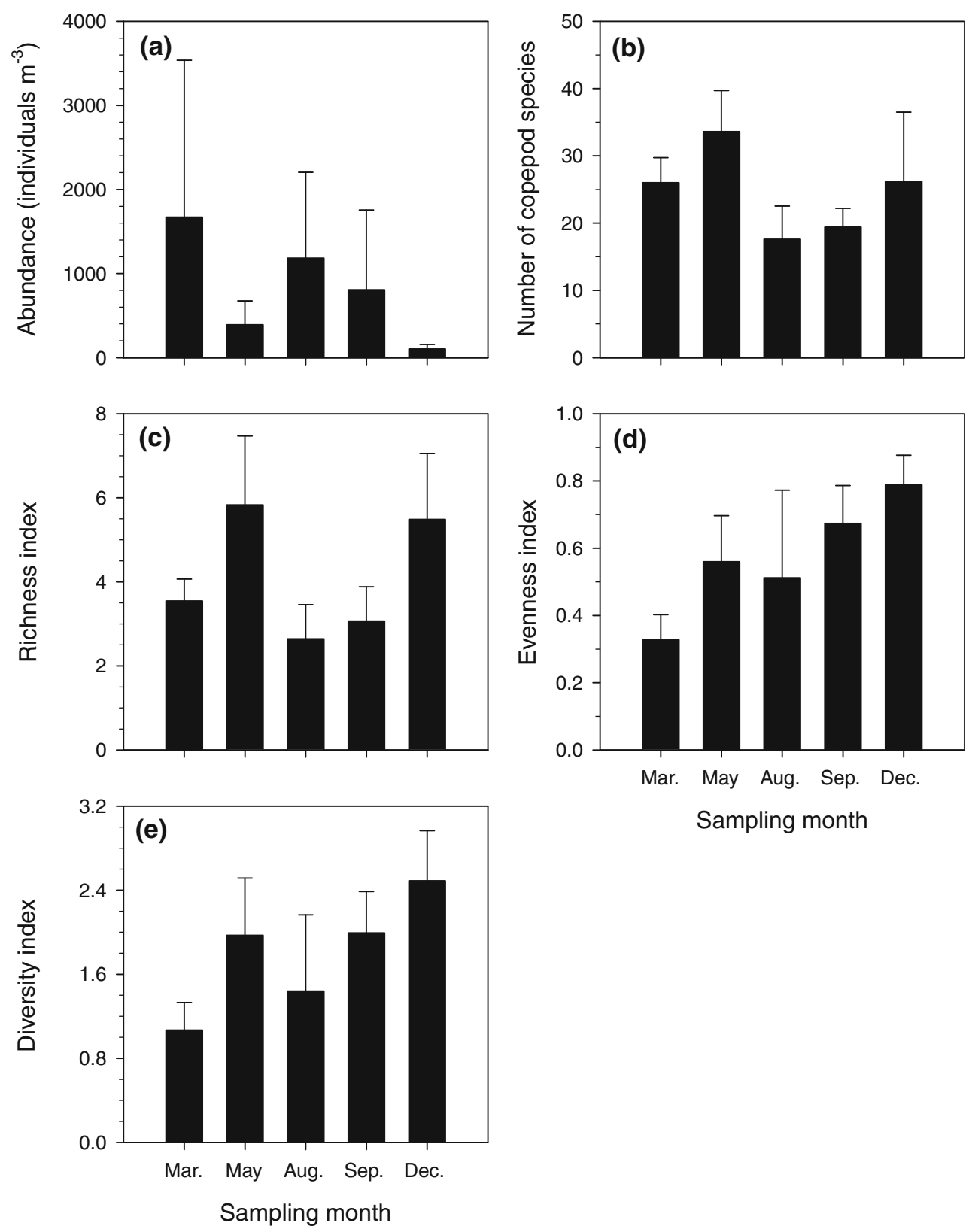

Fig. 6 Comparisons of abundance (a), number of species (b), indices of richness (c), evenness (d), and diversity (e) from five sampling cruises using one-way ANOVA followed by the Tukey's test

species in cold waters $\left(14.42 \pm 0.16^{\circ} \mathrm{C}\right)$, with higher densities during winter and spring when northeast monsoon prevailed. The geographical locations of stations in this study and those of Hwang et al. (2006) were generally influenced by cold water of CCC. Thus, our results are consistent with those of Hwang et al. (2006) in that C. sinicus and C.(D.) affinis belong to cold CCC water species. Their results provide evidence that $\mathrm{CCW}$ can transport zooplankton of cold water to the boundary area of Kuroshio Current off northeast Taiwan. In the cluster results of this study, Group II A contained two dominant species, P. nanus and P. aculeatus. Kâ and Hwang (2011) also reported that these two species were abundant in coastal waters of northeastern Taiwan in September 2009. Their results are consistent with the findings of this study, which identified these two species in samples of August and September. These two species were also recorded in samples of KC (Hsiao et al. 2004, 2011a; Hwang et al. 2007; Kâ and Hwang 2011). Group II B, including 11 copepod species, were widely distributed and commonly found in waters around Taiwan (Shih and Young 1995; Hwang et al. 2006; Dur et al. 2007; Tseng et al. 2008b, c, d; Hsiao et al. 2011b). The results of statistical correlation indicated that copepod species of Group II B live in 


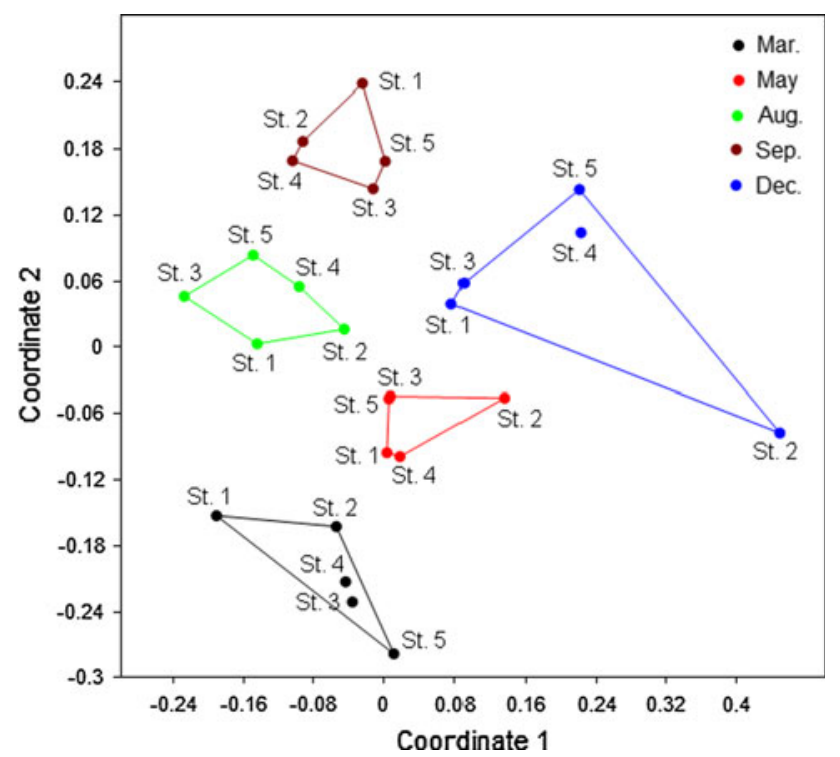

Fig. 7 Non-metric multidimensional scaling (NMDS) of all copepod data from 25 samples collected from five sampling cruises

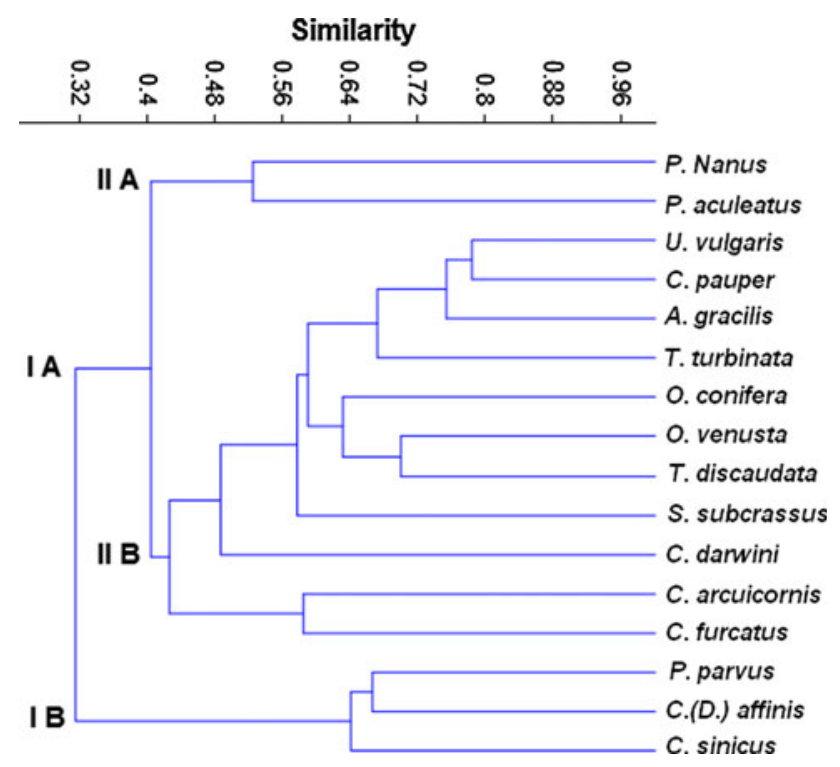

Fig. 8 Dendrogram of the 16 most abundant copepod species (comprising $94.54 \%$ of the total copepod) measured by Bray-Curtis distances. The dendrogram shows the degree of relative similarity of distribution between species in the surface water around Turtle Island (or favor) warm-water masses. Among these species, the abundance of $C$. pauper and $U$. vulgaris was significantly and positively correlated with seawater temperature. The species $T$. turbinata plays a vital role as an indicator of warm-water masses and was abundant in coastal areas of Taiwan (Hwang et al. 2006, 2009; Dur et al. 2007; Tseng et al. 2008c, 2011d). In the present studies, the T. turbinata exhibited the highest RA $(26.89 \%)$ with an average density of $223.3 \pm 548.87$ inds. $/ \mathrm{m}^{3}$ (Table 2), implying that T. turbinata was the most abundant in northern Taiwan.

The highest total abundance record was at Station 1 in March 2010 (Fig. 4a). The T-S curve hints that copepod composition in sample may be influenced by KW (Fig. 3). The top three dominant species in this sample were C.(D.) affinis, $P$. parvus, and $C$. sinicus. These three species belong to a group of cold-water species (Hwang et al. 2004; Hwang and Wong 2005; Dur et al. 2007; Tseng et al. 2008b; Chou et al. 2012). The present results support the evidence of SST satellite images (Fig. 2a) that China coastal water intruded into region off northeastern Taiwan. In addition, the low-temperature water in the present study area might produce negative effect on species in $\mathrm{KW}$ (Chen 1992; Chou et al. 2012). Further, the cold-water copepod species become dominant in sample.

\section{Remarks on Calanoides philippinensis}

The Calanoides philippinensis (Calanoida: Calanidae), recorded in a single sample of May, was noticeable species among all copepods. First, the copepod taxonomic records reviewed by Shih and Young (1995) revealed that this species was not found in the seas around Taiwan. Similarly, Yamaji (1996) did not record this species in waters around Japan. By contrast, our findings are supported by the comprehensive results of Chihara and Murano (1997) and Liu (2008). This species has been reported in the ECS and in the southern area of Kagoshima Island by Chihara and Murano (1997). Furthermore, this species was distributed in SCS and Pacific Ocean adjacent to Mainland China (Liu 2008). However, several studies did not report C. philippinensis in the ECS (Hwang et al. 1998; Liao et al. 2006; Tseng et al. 2008d, 2011c, 2012). Therefore, previous evidence indicates that $C$. philippinensis is not the native copepod in the ECS.

Table 3 Included samples and their mean temperature for associated copepod species of cluster grouping results in Fig. 8

\begin{tabular}{llr}
\hline Cluster group & Included samples & Mean temperature $\left({ }^{\circ} \mathrm{C}\right)$ \\
\hline I B & All samples of March, May, August, and Station 1, 3, 4, and 5 in December & $24.30 \pm 2.58$ \\
II A & Station 2, 3, 4, and 5 in May, Station 2, 4, and 5 in August, & $25.39 \pm 2.39$ \\
& all samples of September and Station 1, 3, 4, and 5 in December & $25.16 \pm 2.58$ \\
\hline II B & All samples &
\end{tabular}


The $\mathrm{KC}$ is proposed as the possible pathway for the transport of $C$. philippinensis to the present study area. A number of previous studies recorded this species living in the $\mathrm{KC}$-influenced area in the northeastern coast of Taiwan (Kâ and Hwang 2011), in the KC system (Hsiao et al. 2004, 2011a), and in the intruded water of KC (Hwang et al. 2007). This species was recorded in the waters around Turtle Island (Lee et al. 2006, 2009) and in the western North Pacific (Kitou and Tanaka 1969).

Tseng et al. (2008a) and Chang et al. (2010) did not identify $C$. philippinensis in their studies of the northern SCS. We traced the origin of location for $C$. Philippinensis based on the records of Chihara and Murano (1997). The previous records indicated that $C$. philippinensis originally appeared in waters of SCS near the equator. Arinardi et al. (1990) and Baars et al. (1990) reported the grazing study for this species in the Banda Sea (Indonesia) and the abundance of $C$. philippinensis in the eastern Banda Sea and northern Arafura Sea, respectively. Previous two reports suggested that $C$. philippinensis belongs to tropical species living in the SCS close to the equator.

\section{Remarks on Calanus sinicus}

The species $C$. sinicus was recorded in samples of March and May in this study. The recorded period exhibits a time lag when compared with previous studies in northwestern Taiwan (Hwang et al. 2006; Dur et al. 2007; Tseng et al. 2008b). The previous studies recorded $C$. sinicus in samples collected before April. The time lag may have been caused by CCC moving from China coast to northeastern Taiwan. As indicated in numerous literature, C. sinicus as an indicator species of ECS cold-water masses (Shih et al. 2000; Hwang and Wong 2005; Tseng et al. 2008b, 2012) originated from Bohai Sea (Chen 1992). In the waters of western Taiwan, the $\mathrm{CCW}$ transported $C$. sinicus to the areas close to Hong Kong (Hwang and Wong 2005), Hainan Island, and Vietnam (Chen and Zhang 1965). On the opposite site in eastern Taiwan, Turtle Island has the lowest recorded latitude that enables $\mathrm{CCW}$ to transport C. sinicus to the area (Lee et al. 2009). Our results confirmed that $C$. sinicus can be identified in the $\mathrm{KC}$. Tseng et al. (2008d) reported C. sinicus during the cruise in July, indicating that this species appeared at stations in southwest East China Sea, except for KC-dominated stations. Considering that the $\mathrm{KC}$ flows northward along the eastern coast of Taiwan to Japan, Tseng et al. (2008d) suggested that water masses mix and exchange with the ECS water in the northeast of Taiwan in the upwelling region. This study provided additional information to that of Tseng et al. (2008d). Sampling time is a critical factor for the study in the Kuroshio region. Tseng et al. (2008d) conducted samplings in July, during the prevailing southwest monsoon.
The $\mathrm{CCW}$ retreated to the northern coast of Mainland China. C. sinicus appeared at all stations in the southern and western East China Sea, except for the stations in the Kuroshio Current region. This may be the reason that Tseng et al. (2008d) did not find $C$. sinicus distributed in the $\mathrm{KC}$ area. Our results confirmed that $C$. sinicus was a seasonal succession species in the Pan-south East China Sea area.

\section{Conclusions}

This study was conducted in the area off northeast Taiwan. The SST images provided evidence that CCC affects the study areas between March and May. The occurrence of indicator species $C$. sinicus in samples confirms that the water masses of East China Sea reached the study area during that period. This study also recorded $C$. philippinensis in the sample of May, suggesting that $C$. philippinensis may originate from southern SCS. The KC may act as a transporter to bring $C$. philippinensis from the southern SCS to the study area. Eventually, the species C. philippinensis can reach Kagoshima Island of southern Japan. The previous and current evidence supports our hypothesis that the SCSW can ride on the Kuroshio Current and reach the southeastern ECS. Furthermore, the species $C$. philippinensis can be regarded as a bioindicator species of SCSW, similar to the species $C$. sinicus, as the bioindicator of cold water in CCC. The present study revealed that (1) $\mathrm{KC}$ plays an important role in transporting tropical species to the study area and (2) the composition and assemblages of copepod community exhibit a seasonal succession because of the interplay of different water masses: the $\mathrm{CCW}$ and the $\mathrm{KW}$ Current in region off northeastern Taiwan.

Acknowledgments The authors would like to thank the members of Prof. J. S. Hwang's laboratory for their assistance in field sampling during five cruises. This study was supported by funding provided by projects NSC 99-2611-M-019-009 and NSC 100-2611-M-019 -010 from National Science Council of Taiwan, ROC. We are thankful for Dr. Ram Kumar, whose help and suggestion improves the manuscript.

\section{References}

Arinardi OH, Baars MA, Oosterhuis SS (1990) Grazing in tropical copepods, measured by gut fluorescence, in relation to seasonal upwelling in the Banda Sea (Indonesia). Neth J Sea Res 25:545-560

Baars MA, Sutomo AB, Oosterhuis SS, Arinardi OH (1990) Zooplankton abundance in the eastern Banda Sea and northern Arafura Sea during and after the upwelling season, August 1984 and February 1985. Neth J Sea Res 25:527-543

Box GEP, Cox DR (1964) An analysis of transformations (with discussion). J R Stat Soc Ser B 26:211-246 
Chan I, Tseng LC, Kâ S, Chang CF, Hwang JS (2012) An experimental study of the gorgonian coral Subergorgia suberosa response to polluted sea water from a former coastal mining site in Taiwan. Zool Stud 51:27-37

Chang WB, Dahms HU, Tseng LC (2010) Abundance, distribution and community structure of planktonic copepods in surface waters of a semi-enclosed embayment of Taiwan during transitions of monsoons. Zool Stud 49:735-748

Chen QC (1992) Zooplankton of China Seas (1). Science Press, Beijing

Chen QC, Zhang SZ (1965) The planktonic copepods of the Yellow Sea and the East China Sea. I. Calanoida. Studia Marina Sinica 7:20-131, 53 plates (in Chinese, with English summary)

Chen QC, Zhang SZ, Zhu CS (1974) On planktonic copepods of the Yellow Sea and the East China Sea. II. Cyclopoida and Harpacticoida. Studia Marina Sinica 9:27-76, 24 plates, (in Chinese, with English summary)

Chihara M, Murano M (1997) An illustrated guide to marine plankton in Japan. Tokyo University Press, Tokyo

Chou C, Tseng LC, Ou CH, Chen QC, Hwang JS (2012) Seasonal succession of planktonic copepods in bight environments of Northeastern Taiwan. Zool Stud (in press)

Dean HK (2008) The use of polychaetes (Annelida) as indicator species of marine pollution: a review. Rev Biol Trop 56:11-38

Dur G, Hwang JS, Souissi S, Tseng LC, Wu CH, Hsiao SH, Chen QC (2007) An overview of the influence of hydrodynamics on the spatial and temporal patterns of calanoid copepod communities around Taiwan. J Plankton Res 29(Supplement 1):i97-i116

Fielman KT, Woodin SA, Lincoln DE (2001) Polychaete indicator species as a source of natural halogenated organic compounds in marine sediments. Environ Toxicol Chem 20:738-747

Gannon JE, Stemberger RS (1978) Zooplankton (especially crustaceans and rotifers) as indicators of water quality. Trans Am Microsc Soc 97:16-35

Grassle JF, Grassle JP (1976) Sibling species in the marine pollution indicator Capitella (Polychaeta). Science 192:567-569

Hammer $\varnothing$, Harper DAT, Ryan PD (2001) PAST: paleontological statistics software package for education and data analysis. Palaeontol Electronica 4:9

Hsiao SH, Lee CY, Shih CT, Hwang JS (2004) Calanoid copepods of the Kuroshio Current east of Taiwan, with a note on the presence of Calanus jashnovi Hulseman, 1994. Zool Stud 43:323-331

Hsiao SH, Fang TH, Shih CT, Hwang JS (2011a) Effects of the Kuroshio Current on copepod assemblages in Taiwan. Zool Stud 50:475-490

Hsiao SH, Kâ S, Fang TH, Hwang JS (2011b) Zooplankton assemblages as indicator of seasonal changes in water masses in the boundary waters between the East China Sea and the Taiwan Strait. Hydrobiologia 663:317-330

Hwang JS, Wong CK (2005) The China Coastal Current as a driving force for transporting Calanus sinicus (Copepoda: Calanoida) from its population centers to waters of Taiwan and Hong Kong during the NE monsoon period in winter. J Plankton Res 27:205-210

Hwang JS, Chen QC, Wong CK (1998) Taxonomic composition and grazing rate of calanoid copepods in coastal waters of northern Taiwan. Crustaceana 71:378-389

Hwang JS, Tu YY, Tseng LC, Fang LS, Souissi S, Fang TH, Lo WT, Twan WH, Hsiao SH, Wu CH, Peng SH, Wei TP, Chen QC (2004) Taxonomic composition and seasonal distribution of copepod assemblages from waters adjacent to nuclear power plant I and II in northern Taiwan. J Mar Sci Technol 12:380-391

Hwang JS, Souissi S, Tseng LC, Seuront L, Schmitt FG, Fang LS, Peng SH, Wu CH, Hsiao SH, Twan WH, Wei TP, Kumar R, Fang TH, Chen QC, Wong CK (2006) A 5-year study of the influence of the northeast and southwest monsoons on copepod assemblages in the boundary coastal waters between the East China Sea and the Taiwan Strait. J Plankton Res 28:943-958

Hwang JS, Dahms HU, Tseng LC, Chen QC (2007) Intrusions of the Kuroshio Current in the northern South China Sea affect copepod assemblages of the Luzon Strait. J Exp Mar Biol Ecol 352:12-27

Hwang JS, Souissi S, Dahms HU, Tseng LC, Schmitt FG, Chen QC (2009) Rank-abundance allocations as a tool to analyze planktonic copepod assemblages off the Danshuei estuary (Taiwan). Zool Stud 48:49-62

Hwang JS, Kumar R, Hsieh CW, Kuo AY, Souissi S, Hsu MH, Wu JT, Liu W, Wang CF, Chen QC (2010) Patterns of zooplankton distribution along the marine, estuarine and riverine portions of the Danshuei ecosystem in northern Taiwan. Zool Stud 49:335-352

Jan S, Wang J, Chern CS, Chao SY (2002) Seasonal variation of the circulation in the Taiwan Strait. J Mar Syst 35:249-268

Kâ S, Hwang JS (2011) Mesozooplankton distribution and composition on the northeastern coast of Taiwan during autumn: effects of the Kuroshio Current and hydrothermal vents. Zool Stud 50:155-163

Kitou M, Tanaka O (1969) Note on a species of Calanoides (Copepoda, Calanoida) from the western North Pacific. Oceanogrl Mag 21:67-81

Lee CY, Shih CT, Hsu CC (2006) Community structure of planktonic copepods in I-Lan Bay and the adjacent Kuroshio waters off northeastern Taiwan. Crustaceana 79:1223-1240

Lee CY, Liu DC, Su WC (2009) Seasonal and spatial variations in the planktonic copepod community of Ilan Bay and adjacent Kuroshio waters off northeastern Taiwan. Zool Stud 48:151-161

Liao CH, Chang WJ, Lee MA, Lee KT (2006) Summer distribution and diversity of copepods in upwelling waters of the Southeastern East China Sea. Zool Stud 45:378-394

Liu R (2008) Checklist of Marine Biota of China Seas. Science Press, Academia Sinica, Beijing

Michie MG (1982) Use of the Bray-Curtis similarity measure in cluster analysis of foraminiferal data. Math Geol 14:661-667

Peng SH, Hung JJ, Hwang JS (2011) Bioaccumulation of trace metals in the submarine hydrothermal vent crab Xenograpsus testudinatus off Kueishan Island, Taiwan. Mar Pollut Bull 63:396-401

Shao KT (1998) Marine ecology. National Press Company, Ming Wen Book Co., Ltd., Taipei

Shih CT, Young SS (1995) A checklist of free-living copepods, including those associated with invertebrates, reported from the adjacent seas of Taiwan. Acta Zool Taiwanica 6:65-81

Shih CT, Hwang JS, Huang WB (2000) Planktonic copepods from an upwelling station north of Taiwan, western North Pacific. J Taiwan Mus 10:19-35

Tseng LC, Dahms HU, Chen QC, Hwang JS (2008a) Copepod assemblages of the northern South China Sea. Crustaceana 81:1-22

Tseng LC, Kumar R, Dahms HU, Chen QC, Hwang JS (2008b) Monsoon driven seasonal succession of copepod assemblages in the coastal waters of the northeastern Taiwan Strait. Zool Stud 47:46-60

Tseng LC, Kumar R, Dahms HU, Chen CT, Souissi S, Chen QC, Hwang JS (2008c) Copepod community structure over a marine outfall area in the northeastern South China Sea. J Mar Biol Assoc UK 88:955-966

Tseng LC, Souissi S, Dahms HU, Chen QC, Hwang JS (2008d) Copepod communities related to water masses in the southwest East China Sea. Helgol Mar Res 62:153-165

Tseng LC, Dahms HU, Hung JJ, Chen QC, Hwang JS (2011a) Can different mesh sizes affect the results of copepod community studies? J Exp Mar Biol Ecol 398:47-55 
Tseng LC, Dahms HU, Hsu NJ, Hwang JS (2011b) Effects of sedimentation on the gorgonian Subergorgia suberosa (Pallas, 1766). Mar Biol 158:1301-1310

Tseng LC, Kumar R, Chen QC, Hwang JS (2011c) Summer distribution of Noctiluca scintillans and mesozooplankton in the Western and Southern East China Sea prior to the Three Gorges Dam operation. Hydrobiologia 666:239-256

Tseng LC, Kumar R, Chen QC, Hwang JS (2011d) Faunal shift between two copepod congeners (Temora discaudata and $T$. turbinata) in the vicinity of two nuclear power plants in southern East China Sea: spatiotemporal patterns of population trajectories over a decade. Hydrobiologia 666:301-315
Tseng LC, Dahms HU, Chen QC, Hwang JS (2012) Mesozooplankton and copepod community structures in the southern East China Sea: the status during the monsoonal transition period in September. Helgol Mar Res. doi:10.1007/s10152-012-0296-1

Webber M, Edwards-Myers E, Campbell C, Webber D (2005) Phytoplankton and zooplankton as indicators of water quality in Discovery Bay, Jamaica. Hydrobiologia 545:177-193

Yamaji I (1996) Illustrations of the marine plankton of Japan. 4th Printing, Hoikushu Publ. Co., Osaka 